\title{
Digital Canon?! Digital Art in the Netherlands 1960-2000
}

\author{
Sanneke Huisman \\ LIMA, Amsterdam
}

Despite an increasingly digital society, digital art is often not collected and preserved in traditional art institutes due to their technological components and anti-institutional stance. In 2017, LIMA initiated the research project Digital Canon?! to generate attention for, and enabling institutional recognition of, digital art and its history by creating a canon of, digital artworks made in the Netherlands between 1960 and 2000. This paper describes the research project and its methodology as well as critically analyses of the digital dived between 'art world art' and digital art and terminology. It concludes on future (institutional) perspectives.

Keywords: digital art, media art, canonisation, art history, technology, analogue technique, art institutions, contemporary art, digital divide, preservation, computational, medium specificity, institutional critique

\section{INTRODUCTION}

Despite the distinguished outcomes generated by the entwinement of art, science, and technology for hundreds of years and especially in the last century, MCA [mainstream contemporary art, ed.] collectors, curators, and institutions struggle to recognize NMA [new media art, ed.] as a valid, much less valuable, contribution to the history of art.

- Edward A. Shanken

In 2017, LIMA initiated a research project to generate attention for digital art and its history, and to encourage museums to acquire digital artworks. Subsequently, the Digital Canon?! project was conceived to initiate a discussion about, as well as compile, a digital art canon of the Netherlands. The project was executed by a core group of specialists in collaboration with numerous experts from the field. This group consisted of researcher and critic Josephine Bosma, artist and tutor Martijn van Boven, researcher and curator Annet Dekker, art historian Sandra Fauconnier, and artist and tutor Jan Robert Leegte. LIMA coordinated the project, and LIMA's director Gaby Wijers and myself, working at LIMA as a freelance curator and researcher, were its supervisors.

\section{PROCESS OF CANONISATION}

The Digital Canon?! project began with no clear framework or rules. Both the methodology and the results were collectively designed over the course of two years. It began with two priorities: selecting and highlighting the 'most important and influential' digital artworks made in the Netherlands, and critically 
reflecting on canonisation. A canon is a tool for remembering, as it both represents and shapes collective memory. However, it is also an instrument of power and a means of selection. Therefore, the project aimed to be critical towards the authoritarian processes that often inform the construction of a canon and to include this criticality from the outset, for instance, by being transparent. Throughout the process, various experts from the international field were invited to reflect upon, contribute to, and provide feedback on the lists of artworks and the methodology. Dieter Daniels, founder of Medien Kunst Netz, advised on how to compile and frame a project with these ambitions. Inke Arns, director of Hartware MedienKunstVerein, suggested calling it 'Unknown Pioneers of Contemporary Art' in an attempt to more directly address the museum field and bypass the so-called digital divide (more on this later). Darko Fritz, author of The Beginning of Digital Arts in the Netherlands (1955-1980), gave critical feedback on the use of the term 'digital' as well as suggesting some little-known but pioneering digital artworks.

\section{The Selection}

After many meetings, debates, longlists, workshops, and testing the collectively formulated selection criteria, twenty artworks were chosen and presented online via the dedicated website digitalcanon.nl. These canonical works were made between 1960 and 2000 on Dutch soil and have contributed strongly to the national field, but are not all by Dutch artists per se. The selection criteria made it possible to 'measure' not only the technological and artistic qualities and pioneering elements of the longlisted works, but also their position within the artists' oeuvre and the role of the artists working in the Dutch field. ${ }^{1}$ Here are the selected works, in chronological order:

- The Senster (1968-1970) by Edward Ihnatowicz, an interactive computer-controlled robotic work (a beast with a resemblance to a dinosaur or a giraffe) measuring 4 metres in height;

- Computerstructuren (1969-1972) by Peter Struycken, a series of pioneering 'computer paintings' consisting of eight black-and-white paintings generated by a computer program;

- Violin Power (1969-1978) by Steina, a performance in which the ZETA violin controls video and image sequences, thus transforming an instrument into an image-generating tool;

- Moiré (1970-1975) by Livinus and Jeep van de Bundt, an abstract analogue video made with a synthesizer built by Livinus van de Bundt, accompanied by synchronised electronic music by his son Jeep van de Bundt;

- Ideofoon I (1970-2013) by Dick Raaijmakers, an installation consisting of 36 loudspeakers, acting as active 'speakers' that compose their own music;

- Points of View (1983) by Jeffrey Shaw, an interactive work utilising Shaw's participatory concept of art that he had been developing since the 1960s, consisting of a stage and protagonists in the form of a three-dimensional computer graphics simulation that was videoprojected onto a screen in front of an audience;

- The Hands (1984-2000) by Michel Waisvisz, a digital musical instrument that consists of two (MIDI) controllers that can be attached to the hands, allowing the performer to develop a physical and tactile relationship between musician and instrument;

- Institute of Artificial Art Amsterdam (IAAA) (1990-present) by Remko Scha, an independent organisation where machines, computers, algorithms and humans work together toward the complete automation of art production;

- $\quad w w w w w w w . j o d i . o r g ~(1995)$ by JODI, a website characterised by chaos and non-functional design that reveals the fundamental characteristics of the early net;

- Breed (1995-2007) by Driessens \& Verstappen (Erwin Driessens and Maria Verstappen), a computer program that generates complex and detailed sculptures using artificial evolution, based on the principles of cell division and genetic evolution;

- Mouchette.org (1996) by Martine Neddam, a fictional, personal online diary of a 13-year-old girl focused on suicide, loneliness, death and violence, with frequent sexual overtones, anticipating the social web; 
- Nara Zoyd/La Zoyd's Pataverse (1996-1998) by Yvonne Le Grand, a virtual persona whose virtual life began on the collaborative filtering community website Firefly.

- clickclub (1996-2001) by Peter Luining, a playfully critical website with images that all link to new pages with animations, images, interactive pages, and new links, often with stimulating, sometimes sexually themed content, provoking the user to keep clicking;

- the living (1997-1998) by Debra Solomon, a performative project in which the artist manifests herself in CU-SeeMe, software that enables online chat boxes with live video connections;

- Being Human (1997-2007) by Annie Abrahams, a collection of dynamic, interlinked, netspecific works in which the artist explores the possibilities and limits of online communication.

- \#11, Marey <-> Moiré (1999) by Joost Rekveld, an abstract 35mm cinemascope film that navigates to forgotten realms of science and technology by investigating the pioneering work of Étienne-Jules Marey and Ernst Moiré in the field of photography;

- Scrollbar Composition (2000) by Jan Robert Leegte, a web-based artwork in which the webpage is divided into planes by moving scrollbars, thereby creating an abstract composition and highlighting the sculptural elements of the net;

- Spatial Sounds $(100 \mathrm{~dB}$ at $100 \mathrm{~km} / \mathrm{h})(2000)$ by Marnix de Nijs and Edwin van der Heide, an interactive installation comprising a speaker mounted onto a rotating arm that scans the surrounding space for visitors and reacts to their presence;

- TST (2000) by Bas van Koolwijk, a series of abstract video compositions, compiled from digitally re-modelled video artefacts;

- Agora Phobia (digitalis) (2000-2009) by Lancel/Maat (Karen Lancel and Hermen Maat), an interactive installation and performance consisting of an inflatable Isolation Pillar that is placed in public space, exploring the experiences and imaginations of being (un)safe and isolated.

\section{THE ROLE OF THE INSTITUTE: EXPANDED INSTITUTIONAL CRITIQUE OR DIGITAL DIVIDE?}

A statement by Oliver Grau in his 2016 essay 'The Complex and Multifarious Expressions of Digital Art and Its Impact on Archives and Humanities' is applicable to the works selected for the digital canon:

All these examples demonstrate that digital media art can deal with questions and challenges of our time in an experimental and participatory way, where traditional art media could simply offer metaphorical approaches. In the best humanistic tradition, digital media art takes on the big contemporary questions, dangers, and proposed transformations, yet it is not adequately collected, documented, and preserved by traditional museums and art institutions. ${ }^{2}$

Digital art is more directly embedded in our - increasingly digital - society since it both makes use of and reflects on the social implications of contemporary technology. Paradoxically, these artworks are regularly misunderstood and not collected because of their use of technological devices. Digital artworks are often primarily perceived as merely technological, instead of artworks about technology or artworks that has been made using technology. It is part of the 'digital divide': the division between 'art world art' and 'digital art'. This discussion started with Claire Bishop's much talked about eponymous article in Artforum in 2012, in which she critically investigated the absence of - an interesting - artistic use of digital technologies: 'While many artists use digital technology, how many really confront the question of what it means to think, see, and filter affect through the digital? How many thematize this, or reflect deeply on how we experience, and are altered by, the digitization of our existence?" ${ }^{3}$ Although in the article the art critic showed interest in digital art and digital technology, she seemed to have overlooked many existing media and digital artworks; artworks that aren't part of the mainstream contemporary art field, probably dismissed because of their technicality. It is a catch-22 that is brought to the fore by art 
historian Edward A. Shanken in his essay 'Contemporary Art and New Media. Digital Divide or Hybrid Discourse?'. He fuels the debate by pointing out that in her article Bishop dismisses the field of digital and new media art, thereby confirming the digital divide that she herself wanted to address. Furthermore, preservation issues broaden the gap between the field of contemporary art and digital art. We must consider the fact that digital artworks are hard to preserve because 1) the hardware and software that they rely on rapidly becomes obsolete, 2) they exist in multiple versions, and 3) are supposedly immaterial, complicating their position within a traditional institutional framework that is - still! - highly mediumoriented. Shanken refutes this argument of immateriality as an obstacle that perpetuates the digital divide by highlighting the art market's acceptance of previous forms of immaterial art: 'The recent popularity and collectability of video art demonstrates MCA's [mainstream contemporary art, ed.] ability and desire to commodify relatively ephemeral art forms for which there previously was no market. ${ }^{4}$

Even if this digital divide can be debated or confuted, it can't be denied that digital art sometimes displays certain incongruities with regards to contemporary art and art history. It can be characterised by an anti-institutional stance comparable to the discourse of institutional critique that emerged in the late 1960s. At that time, artists such as Michael Asher, Daniel Buren and Hans Haacke revealed the power structures of the institutionalised art world. Asher highlighted the organisational inner workings of galleries and museums, Haacke took a political stand by tracking the origin of funding and showcasing the conflicting positions of art and money; Buren reached the 'degree zero of painting' in a newfound readymade. With his characteristically striped painting, Buren showed the different perceptions of the very same artwork either inside or outside the museum walls. But what if this 'outside' is a fully functioning communication network? Digital artists do not merely criticise the institution from an insiders' position. By using mass media and digital technologies, these works were born, and seem to function, outside of the institutional framework, thereby creating their own institutes and infrastructures. This increased after the arrival of the Internet, the communication infrastructure that drastically changed society and was hailed as the 'promised land' that would facilitate a more democratic art field. As Axelle Van Wynsberghe points out in her article 'Manifesto for Canonisation in a Flat World':

The digital art field has created its own relatively insular cultural milieu, which functions based on different principles of collection, preservation, exhibition, and contextualisation than that of the traditional art world. From its mailing lists and surf clubs, to its hosting of artist-initiated web-based curatorial projects, it has largely established itself in opposition to long-held notions of 'hierarchical' and 'elitist' traditional institutions.

\section{TERMINOLOGY: DIGITAL VERSUS COMPUTATIONAL}

Terms and labels can contribute to rejection as much as the validation of the opposition of mainstream contemporary art and digital art. On the one hand, an accurate description of the use of technology is needed, while on the other, many of the current terms seem to emphasise the digital divide. Their medium specific - and thus technological - orientation often contributes to the misunderstanding of these artworks. With regard to digital art and the Digital Canon?! project in particular, terminology therefore was another issue to consider. The terms 'computational' and more specifically, 'computational aesthetics', as coined by M. Beatrice Fazi and Matthew Fuller, were reflected upon as broader definitions of 'digital'. As Fazi and Fuller state:

We understand computation as a method and a force of organization, quantification, and rationalization of reality by logico-mathematical means. The computational precedes yet grounds the digital in its technical, social, and cultural manifestations: it finds in digital technologies a fast, efficient, and reliable technique of automation and distribution, yet remains a notion wider and more powerful than the digital tools that it subtends. ${ }^{6}$ 
By investigating the medium-specific qualities of digital art, Fazi and Fuller aim to look beyond the mere modernist preoccupations of Clement Greenberg's use of medium specificity by determining computational 'as much a condition as it is a medium'. 'Within the framework of the Digital Canon?! project, 'computational aesthetics' was evaluated as a term that could enable the inclusion of non-digital works, for example, generative artworks, as Fazi and Fuller state: 'Computation, we contend, is a systematization of reality via discrete means such as numbers, digits, models, procedures, measures, representations and highly condensed formalizations of relations between such things. ${ }^{8}$ However, the term excludes artworks that reflect upon mass media and telecommunications and/or artworks that make use of analogue techniques, thus being based on non-discrete signals. A broader focus was therefore desired. The Digital Canon?! project focused on the influence of the selected artworks on the field of digital art and culture. Influential artists like Raaijmakers and Van der Bundt reflect on and make use of analogue techniques. In the case of Raaijmakers, Ideofoon I can even be considered a manifestation and celebration of the possibilities of the analogue since the vibration of the speakers is a result of electronic waves. Nevertheless, the influence of these pioneers on later digital artists cannot be underestimated, as is apparent, for instance, in the current activities in live cinema and sound art.

\section{CONCLUSIONS AND FUTURE PERSPECTIVES}

The history of digital art cannot be limited to either technical specifications or artistic and arthistorical preoccupations. The Digital Canon?! project has taken account of the multifaceted aspects of the discipline by paying attention to both the 'technological' and supposedly 'anti-institutional stance' of digital art in the debate on the possibilities of its canonisation from an art-historical perspective. Artists working with digital technologies have not only used and developed these technologies in artistic and social ways; they have also questioned the function and role of this pivotal issue for both society and the arts. In the end, the question if these artworks might or might not fully function outside the field of (mainstream contemporary) art is irrelevant, as is the question whether they make use of or build on analogue or digital techniques (or both). The fact is that the significance of these artworks can be found in the sum of their parts: their use of tools, their references, their oppositions and their position in society; all the elements that paradoxically make the artworks harder to categorise, show, maintain and preserve. It is because of their unique - and often complex - position that they need to be shown and remembered by future generations. And where better to do so than in a museum, the pre-eminent caretaker? If we are to delegate the role of 'preserving institute' to museums in the present day, then surely these institutions must take on this task.

\section{ENDNOTES}

1. See digitalcanon.nl for the full list of selection criteria.

2. Grau 2016, 25.

3. Bishop 2012.

4. Shanken 2016, 464.

5. Van Wynsberghe 2019.

6. Fazi and Fuller 2016, 281.

7. Ibid., 283.

8. ibid. 


\section{REFERENCES}

Bishop, C. (2012, September). Digital Divide: Contemporary Art and New Media. Artforum, 434-441.

Fazi M.B., \& Fuller M. (2016). Computational Aesthetics. In: Paul C. (ed.), A Companion to Digital Art. Hoboken: Wiley Blackwell, 281-96.

Grau, O. (2016). The Complex and Multifarious Expressions of Digital Art and Its Impact on Archives and Humanities. In: Paul C. (ed.), A Companion to Digital Art. Hoboken, New Jersey, United States: Wiley-Blackwell, 23-45.

Paul C. (ed.). (2016). A Companion to Digital Art. Hoboken: Wiley Blackwell,

Shanken, E. A. (2016). Contemporary Art and New Media Digital Divide or Hybrid Discourse? In: Paul C. (ed.), A Companion to Digital Art. Hoboken, New Jersey, United States: Wiley-Blackwell, 463-81.

Van Wynsberghe, A. (2019). Manifesto for Canonization in a Flat World. Retrieved from www.digitalcanon.nl 